\title{
COVID19 antibody detection using lateral flow assay tests in a cohort of convalescent plasma donors
}

\author{
Brett Ragnesola ${ }^{1 \dagger}$, Daniel Jin ${ }^{1 \dagger}$, Christopher C. Lamb $2,3,4^{*} \oplus$, Beth H. Shaz ${ }^{1}$, Christopher D. Hillyer ${ }^{1}$ \\ and Larry L. Luchsinger ${ }^{\text {* }^{*}}$
}

\begin{abstract}
Objective: COVID19 has caused a global and ongoing pandemic. The need for population seroconversion data is apparent to monitor and respond to the pandemic. Using a lateral flow assay (LFA) testing platform, the seropositivity in 63 New York Blood Center (NYBC) Convelescent Plasma (CP) donor samples were evaluated for the presence of COVID19 specific lgG and lgM.
\end{abstract}

Results: CP donors showed diverse antibody result. Convalescent donor plasma contains SARS-CoV-2 specific antibodies. Weak antibody bands may identify low titer CP donors. LFA tests can identify antibody positive individuals that have recovered from COVID19. Confirming suspected cases using antibody detection could help inform the patient and the community as to the relative risk to future exposure and a better understanding of disease exposure.

Keywords: Covid-19, Antibody testing, Convalescent plasma

\section{Introduction}

Severe acute respiratory syndrome coronavirus 2 (SARSCoV-2) has caused over 4012,000 infections and $>32,000$ deaths in New York State alone [1]. Due to delay in testing and asymptomatic infections the true number of cases are unknown. Few reports have characterized the prevalence of seroconversion in community populations $[2,3]$. Seroconversion, the process in which a patient accumulates antigen-specific antibodies against an epitope, is the first step towards the development of adaptive immunity against pathogens. Although it is not an assurance of protection against future infections, positive seroconversion is an informative measure of previous viral infectivity

\footnotetext{
*Correspondence: chrislamb@biosolutionsservices.com; LLuchsinger@nybc. org

${ }^{\dagger}$ Brett Ragnesola and Daniel Jin contributed equally to this work

${ }^{1}$ New York Blood Center Lindsley F. Kimball Research Institute, 310 E 67th Street, New York, NY 10065, USA

2 BioSolutions Services, 92 Irving Avenue, Englewood Cliffs, NJ 07632, USA Full list of author information is available at the end of the article
}

within the population. To assess the seroconversion of a community, antibody testing with high sensitivity and specificity that is also easily available is necessary.

However, a crucial step in understanding the test characteristics is to ensure the assay detects antibodies in individuals with a previous documented disease. One study suggests that $75 \%$ of patients with a confirmed PCR test had a positive antibody IgG and $20 \%$ were weakly positive [4]. Another study showed $100 \%$ seroconversion in COVID19 patients and three patterns of IgM and IgG responses: synchronous seroconversion of IgG and IgM, IgM seroconversion earlier than that of IgG, and IgM seroconversion later than that of IgG [3]. In addition, assay characteristics such as antigen target (nucleocapsid and/or spike glycoprotein), total (IgG and IgM) versus IgG only, and their sensitivity and specificity are important in defining seroconversion rates [5]. Thus, more studies with various antibody tests are needed to understand seroconversion of an infected population. 
In response to this need for antibody testing, a lateral flow assay (LFA) was developed to provide rapid point of care diagnostic testing of COVID19 antibodies. The LFA test is able to detect specific SARS-CoV-2 antibodies and differentiate between IgG and IgM immunoglobin classes in a rapid, point of care test using either whole blood, plasma or serum [6]. The test principle is based on the receptor-binding domain (RBD) of the spike and nucleocapsid proteins. The cassette has both a dye pad which contains colloidal gold coupled with Recombinant 2019novel coronavirus nucleocapsid protein and a dye pad which contains colloidal gold coupled with Recombinant 2019-novel coronavirus Spike Protein (Si Subunit). Thus, LFAs are potentially useful assays that require low sample input and minimum processivity. In this study, we report the sensitivity and specificity of Clungene ${ }^{\circledR}$ SARS-CoV-2 IgG/IgM Rapid Test Cassettes in determining the presence of binding antibodies in convalescent plasma (CP) donor samples with previously documented COVID19.

\section{Main text \\ Methods}

Convalescent donor plasma was collected by the New York Blood Center (NYBC) with written consent from patients in accordance with NYBC Institutional Review Board protocols. All donors had self-reported documented COVID19 disease by positive SARS-CoV-2 RTPCR test (manufacturer and documentation not provided from referring institution of CP donors), had complete resolution of symptoms at least 14 days prior to donation, and otherwise met all criteria for donating blood consistent with FDA's policy on the Collection of COVID19 Convalescent Plasma [1]. As a negative control, fresh frozen plasma was used that was collected prior to the beginning of the epidemic. Clungene ${ }^{\circledR}$ SARS-CoV-2 (COVID-19) IgG/IgM Rapid Test Cassettes were used to determine the presence of SARS-CoV-2-specific IgG and IgM. The manufacturer of the Cassette (Hangzhou Clongene Biotech Co., Ltd., Hangzhou, China) validated this immunoassay for the qualitative detection of IgG and IgM antibodies to SARS-CoV-2 and these data were submitted to FDA as part of their Emergency Use Authorization [7].

To perform assays, $20 \mathrm{~mL}$ of human plasma was applied to the sample pad followed by two drops of proprietary running buffer. Tests were analyzed after $15 \mathrm{~min}$. Following incubation, high resolution images were taken of detection zone and saved as JPEG for reference and analysis. Positive and negative IgG/IgM band determinations were made by visual inspection with accordance to manufacturer instructions (Fig. 1a, b). All tests were performed under a NYBC IRB approved protocol using four independently trained operators.

\section{Results}

Convalescent donor plasma contains SARS-CoV-2 specific antibodies. Using $\mathrm{CP}$ donors as a prospectively positive population, we tested $63 \mathrm{NYBC} C \mathrm{CP}$ donor samples for the presence of SARS-CoV-2 specific IgG and IgM. CP donors showed diverse antibody result profiles with the LFA test, including strong and weak bands as compared to FFP negative control (Fig. 1c, Table 1). All samples yielded an interpretable result with no invalid results. Overall, $88.9 \%(56 / 63)$ of CP donors were considered positive. $87.3 \%(55 / 63)$ of CP donors were positive for IgG and $50.8 \%$ (32/63) of CP donors were positive for IgM (Fig. 2a, b).

With regard to negative samples, $11.1 \%$ (7/63) of CP donors were $\operatorname{IgG}^{\mathrm{Neg}}$ and $\operatorname{IgM}^{\mathrm{Neg}}, 1.6 \%$ (1/63) were $\operatorname{IgG}^{\mathrm{Neg}}$ and $\operatorname{IgM}^{\mathrm{Pos}}$ and $38.1 \%(24 / 63)$ were $\operatorname{IgG}^{\mathrm{Pos}}$ and IgM $^{\mathrm{Neg}}$ (Fig. 2c). In contrast, all FFP samples were $\mathrm{IgG}^{\mathrm{Neg}}$ and $80 \%(8 / 10)$ were $\mathrm{IgM}^{\mathrm{Neg}}$. These data suggest that LFA tests possess a high degree of sensitivity (87.3\% IgG, 50.8\% IgM) and specificity (100.0\% IgG, $80.0 \%$ IgM) for detecting SARS-CoV-2 specific antibodies. Given all CP donors were collected more than 14 days since date of last symptom, when the IgM tests would have performed, it is not surprising that the IgM results were low since IgM immunoglobins likely develop early in response to infection [8].

Weak antibody bands may identify low titer CP donors. Recent studies suggest that a significant percentage of convalescent individuals may have low SARS-CoV-2 IgG or IgM titers $[4,9]$. We also inferred from conducting LFA assays that potential differences in antibody levels may occur in the $\mathrm{CP}$ donor population. However, LFA tests are designed to perform qualitative, and not quantitative, analysis as stated in the manufacturer's instructions. Nevertheless, to document this phenomenon, trained experimenters subjectively delineated positive results as 'strong' or 'weak' relative to the band intensity produced by each $\mathrm{CP}$ donor sample (Fig. 1c).

To confirm reproducibility, we re-tested random samples $(n=16)$ to explore whether CP donor samples could provide reproducible results (Fig. 2d, Table 1). Between replicates of paired results, $56.25 \%(9 / 16)$ of samples were consistently positive, $6.25 \%(1 / 16)$ was consistently negative, and $37.5 \%(6 / 16)$ were inconsistent. With regard to inconsistency, these bands were almost always visually weak (4/6). These data suggest that certain CP donors may have low levels of SARS$\mathrm{CoV}-2$ antibodies and may account for inconsistency between results, while data available from the manufacturer did report any difference related to batches $(\mathrm{n}=3)$, operators $(\mathrm{n}=2)$, runs $(\mathrm{n}=2)$ or time (15 days). 


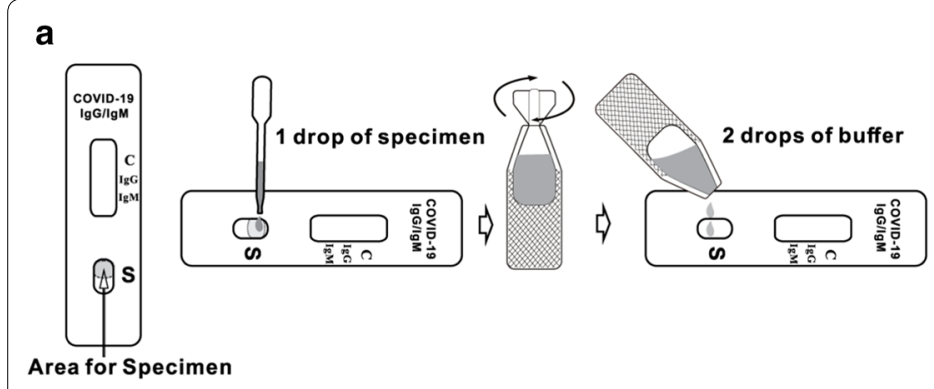

b

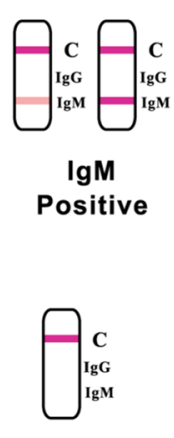

Negative

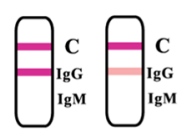

$\lg \mathbf{G}$

Positive

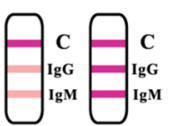

$\lg G / \lg M$

Positive

C

129416 (CP)

110958 (CP)

strong $(+)$

129466 (CP)

weak (+)

strong $(+)$

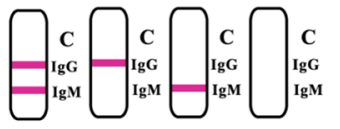

weak (+)

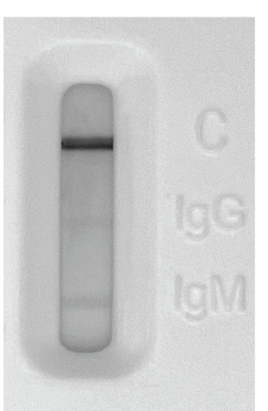

900220 (FFP)

negative (-)

negative (-)

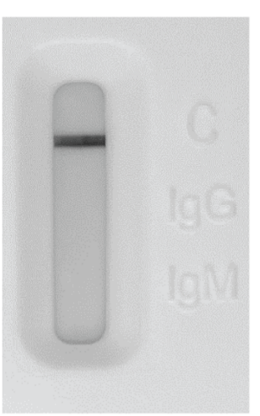

Fig. 1 a Procedural schematic for CLUNGENE ${ }^{\circledR}$ Immunoassay. One drop is equal to 20 uL. b Visual interpretation guide for assays. c Representative convalescent donor plasma (CP) or frozen fresh plasma (FFP) assay result images

\section{Discussion}

Our study analyzed blood samples from COVID19 convalescent plasma donors to determine whether antibodies are detected using a LFA in this population. We found that the CLUNGENE ${ }^{\circledR}$ SARS-COV-2 VIRUS (COVID19) IgG/IgM LFA test possesses high sensitivity and specificity for COVID19 antibodies. The LFA test was easy to use with properly trained staff. Results were interpretable within $15 \mathrm{~min}$ and the internal procedural control confirmed that sufficient specimen volume, adequate membrane wicking and correct procedural technique were used. Since documented positive PCR tests or comparison to other antibody testing platforms were unavailable, we cannot state that the 7 negative donors in fact were infected or if they have antibody. Even if CP donor infection data were available, it may also be possible, and is probable, that some $\mathrm{CP}$ donors produced low amounts of antibodies that is specific to the immunological response unique to each individual, thus, below the detection limit of the LFA. The IgG results are consistent with the manufacturer's $97.4 \%$ clinical performance data which showed positive IgG agreement with known positive RT-PCR test. The IgM results are consistent with recently published data which shows that IgM can persist more than 23 days after symptom onset and can be earlier, synchronous or later than IgG.

\section{Conclusions}

Most (90\%) COVID19 convalescent donors seroconverted, demonstrating the potential of LFA tests to identify antibody positive individuals that have recovered from COVID19. Confirming suspected SARS-CoV-2 cases using antibody detection at the point of care could help inform the patient and the community as to the relative risk to future SARS-CoV2- exposure and a better understanding of disease exposure. However, a coherent description of the immunological response and antiviral antibody activity (i.e. neutralizing activity) is warranted to definitively use antibody presence to prognose future disease potential [10]. This study highlights the relevance of serological testing to support accurate estimates of the extent of the COVID-19 pandemic and the potential to assess a patient response to SARS-CoV-2 infection using antibody detection. 
Table 1 Compilation of LFA testing results

\begin{tabular}{|c|c|c|c|c|c|}
\hline Sample\# & Original/duplicated & Experimenter & Sample ID & IgG result & IgM result \\
\hline 1 & Original & A & 73,573 & Weak+ & Negative \\
\hline 2 & Original & B & 96,138 & Negative & Negative \\
\hline 3 & Original & C & 96,245 & Strong+ & Negative \\
\hline 4 & Original & B & 110,766 & Strong+ & Strong+ \\
\hline 5 & Original & A & 110,773 & Strong+ & Negative \\
\hline 6 & Original & B & 110,781 & Strong+ & Strong+ \\
\hline 7 & Original & B & 110,782 & Strong+ & Negative \\
\hline 8 & Original & A & 110,788 & Strong+ & Negative \\
\hline 9 & Original & A & 110,790 & Strong+ & Weak+ \\
\hline 10 & Original & A & 110,802 & Strong+ & Weak+ \\
\hline 11 & Original & A & 110,810 & Strong+ & Weak+ \\
\hline 12 & Original & A & 110,811 & Weak+ & Weak+ \\
\hline 13 & Original & C & 110,958 & Strong+ & Weak+ \\
\hline 14 & Original & C & 110,973 & Strong+ & Strong+ \\
\hline 15 & Original & C & 110,984 & Strong+ & Negative \\
\hline 16 & Original & B & 110,988 & Strong+ & Negative \\
\hline 17 & Original & C & 111,846 & Strong+ & Strong+ \\
\hline 18 & Original & B & 111,847 & Strong+ & Weak+ \\
\hline 19 & Original & C & 111,848 & Strong+ & Strong+ \\
\hline 20 & Original & C & 111,857 & Strong+ & Negative \\
\hline 21 & Original & C & 116,229 & Strong+ & Strong+ \\
\hline 22 & Original & B & 117,031 & Strong+ & Weak+ \\
\hline 23 & Original & B & 117,032 & Strong+ & Strong+ \\
\hline 24 & Original & B & 117,055 & Negative & Negative \\
\hline 25 & Original & B & 117,072 & Weak+ & Negative \\
\hline 26 & Original & A & 117,102 & Strong+ & Weak+ \\
\hline 27 & Original & B & 117,131 & Negative & Negative \\
\hline 28 & Original & C & 117,707 & Strong+ & Negative \\
\hline 29 & Original & C & 127,010 & Strong+ & Negative \\
\hline 30 & Original & C & 127,161 & Negative & Negative \\
\hline 31 & Original & C & 127,168 & Negative & Negative \\
\hline 32 & Original & $C$ & 127,171 & Strong+ & Negative \\
\hline 33 & Original & $C$ & 127,179 & Strong+ & Negative \\
\hline 34 & Original & D & 129,402 & Strong+ & Strong+ \\
\hline 35 & Original & A & 129,404 & Strong+ & Strong+ \\
\hline 36 & Original & D & 129,405 & Strong+ & Negative \\
\hline 37 & Original & A & 129,408 & Negative & Negative \\
\hline 38 & Original & B & 129,412 & Strong+ & Weak+ \\
\hline 39 & Original & B & 129,414 & Strong+ & Weak+ \\
\hline 40 & Original & B & 129,416 & Strong+ & Strong+ \\
\hline 41 & Original & A & 129,420 & Strong+ & Strong+ \\
\hline 42 & Original & D & 129,427 & Strong+ & Negative \\
\hline 43 & Original & A & 129,437 & Weak+ & Strong+ \\
\hline 44 & Original & A & 129,455 & Strong+ & Strong+ \\
\hline 45 & Original & A & 129,466 & Weak+ & Strong+ \\
\hline 46 & Original & A & 129,471 & Strong+ & Strong+ \\
\hline 47 & Original & A & 129,483 & Strong+ & Weak+ \\
\hline 48 & Original & B & 129,491 & Strong+ & Strong+ \\
\hline 49 & Original & B & 129,790 & Strong+ & Negative \\
\hline
\end{tabular}


Table 1 (continued)

\begin{tabular}{|c|c|c|c|c|c|}
\hline Sample\# & Original/duplicated & Experimenter & Sample ID & IgG result & IgM result \\
\hline 50 & Original & A & 129,845 & Weak+ & Negative \\
\hline 51 & Original & B & 129,857 & Strong+ & Strong+ \\
\hline 52 & Original & C & 129,884 & Strong+ & Negative \\
\hline 53 & Original & C & 129,900 & Strong+ & Negative \\
\hline 54 & Original & C & 97,591 & Strong+ & Negative \\
\hline 55 & Original & B & 97,594 & Strong+ & Weak+ \\
\hline 56 & Original & C & 97,595 & Strong+ & Strong+ \\
\hline 57 & Original & C & 97,643 & Strong+ & Negative \\
\hline 58 & Original & B & 97,723 & Strong+ & Weak+ \\
\hline 59 & Original & B & 111,538 & Strong+ & Negative \\
\hline 60 & Original & B & 111,584 & Negative & Negative \\
\hline 61 & Original & C & 117,001 & Strong+ & Negative \\
\hline 62 & Original & C & 129,298 & Strong+ & Negative \\
\hline 63 & Original & B & 129,349 & Negative & Weak+ \\
\hline FFP 1 & Original & C & FFP-181,484 & Negative & Strong+ \\
\hline FFP 2 & Original & A & FFP-203,529 & Negative & Weak+ \\
\hline FFP 3 & Original & A & FFP-222,235 & Negative & Negative \\
\hline FFP 4 & Original & A & FFP-222,252 & Negative & Negative \\
\hline FFP 5 & Original & A & FFP-222,353 & Negative & Negative \\
\hline FFP 6 & Original & A & FFP-222,427 & Negative & Negative \\
\hline FFP 7 & Original & A & FFP-222,604 & Negative & Negative \\
\hline FFP 8 & Original & A & FFP-222,633 & Negative & Negative \\
\hline FFP 9 & Original & A & FFP-900,220 & Negative & Negative \\
\hline FFP 10 & Original & A & FFP-906,227 & Negative & Negative \\
\hline 4 & Duplicated & D & 110,766 & Strong+ & Strong+ \\
\hline 4 & Duplicated & B & 110,766 & Strong+ & Strong+ \\
\hline 6 & Duplicated & D & 110,781 & Strong+ & Weak+ \\
\hline 6 & Duplicated & B & 110,781 & Strong+ & Strong+ \\
\hline 7 & Duplicated & D & 110,782 & Strong+ & Negative \\
\hline 7 & Duplicated & B & 110,782 & Strong+ & Negative \\
\hline 22 & Duplicated & D & 117,031 & Negative & Negative \\
\hline 22 & Duplicated & B & 117,031 & Strong+ & Weak+ \\
\hline 23 & Duplicated & D & 117,032 & Strong+ & Negative \\
\hline 23 & Duplicated & B & 117,032 & Strong+ & Strong+ \\
\hline 24 & Duplicated & D & 117,055 & Negative & Negative \\
\hline 24 & Duplicated & B & 117,055 & Negative & Negative \\
\hline 25 & Duplicated & D & 117,072 & Negative & Negative \\
\hline 25 & Duplicated & B & 117,072 & Weak+ & Negative \\
\hline 34 & Duplicated & D & 129,402 & Strong+ & Strong+ \\
\hline 34 & Duplicated & B & 129,402 & Strong+ & Weak+ \\
\hline 36 & Duplicated & D & 129,405 & Strong+ & Negative \\
\hline 36 & Duplicated & B & 129,405 & Strong+ & Negative \\
\hline 38 & Duplicated & D & 129,412 & Strong+ & Negative \\
\hline 38 & Duplicated & B & 129,412 & Strong+ & Weak+ \\
\hline 39 & Duplicated & D & 129,414 & Strong+ & Negative \\
\hline 39 & Duplicated & B & 129,414 & Strong+ & Weak+ \\
\hline 40 & Duplicated & D & 129,416 & Strong+ & Strong+ \\
\hline 40 & Duplicated & B & 129,416 & Strong+ & Strong+ \\
\hline 42 & Duplicated & $D$ & 129,427 & Strong+ & Negative \\
\hline
\end{tabular}


Table 1 (continued)

\begin{tabular}{lllclc}
\hline Sample\# & Original/duplicated & Experimenter & Sample ID & lgG result & IgM result \\
\hline 42 & Duplicated & B & 129,427 & Negative & Negative \\
48 & Duplicated & D & 129,491 & Strong+ \\
48 & Duplicated & B & 129,491 & Strong+ \\
49 & Duplicated & D & 129,790 & Strong+ \\
49 & Duplicated & B & 129,790 & Strong+ \\
51 & Duplicated & D & 129,857 & Strong+ & Negative \\
51 & Duplicated & B & 129,857 & Strong+ \\
\hline
\end{tabular}

a

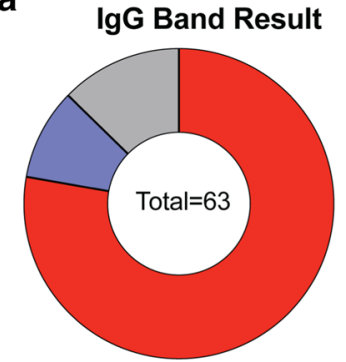

Strong Result $77.8 \%$ (49)

Weak Result $9.5 \%(6)$

$\square$ Negative Result $12.7 \%(8)$

b

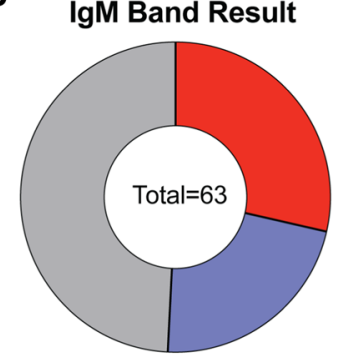

Strong Result

$28.6 \%(18)$

Weak Result $22.2 \%$ (14)

Negative Result $49.2 \%$ (31)

\section{c}

\section{Overall CP Donor Test Results}

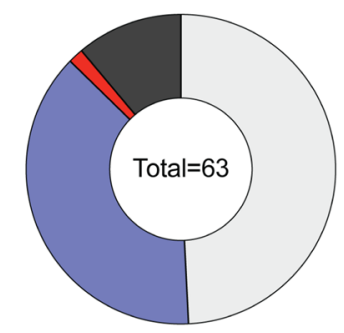

$\lg G^{\text {Pos }} / \lg M^{\text {Pos }}$ $49.2 \%(31)$

$\operatorname{lgG}^{\text {Pos }} / \lg \mathrm{M}^{\text {Neg }}$ $38.1 \%(24)$

$\lg G^{\text {Pos }} / \lg M^{\text {Pos }}$ $1.6 \%(1)$

$\lg G^{\text {Pos }} / \lg \mathrm{M}^{\text {Pos }}$ $11.1 \%(7)$

\section{d}

\section{Duplicate Testing of CP Donor Plasma Samples}
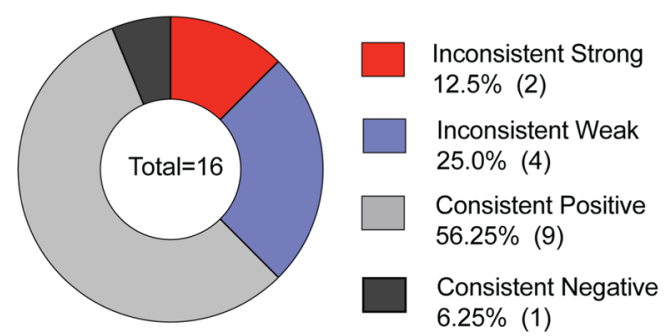

Fig. 2 a Frequency of IgG assay results from CP donor samples. $\mathbf{b}$ Frequency of IgM assay results from CP donor samples. c Overall $\mathrm{CP}$ donor test result. $\mathbf{d}$ Frequency of assay result duplication using identical CP donor samples

\section{Limitations}

Our study has several limitations, including but not limited to:

- Samples were not tested for virus neutralization; therefore neutralizing activities of the detected IgG antibodies are not known.

- The small sample size of patients and the absence of documented PCR test results makes it difficult to determine the relationship between antibody response and clinical course.

- More detailed investigation of the reproducibility of the test is warrented.

\section{Abbreviations}

LFA: Lateral flow assay; SARS-CoV-2 aka COVID19: Severe acute respiratory syndrome coronavirus 2; CP: Convalescent plasma; IgG: Immunoglobulin G; IgM: Immunoglobulin M; NYBC: New York Blood Center; PCR: Polymerase chain reaction.

\section{Acknowledgements}

We would like to thanks Ryan Dagenais for his editorial support with the manuscript; Ryan's services were funded by BioSolutions Services LLC.

\section{Authors' contributions}

$\mathrm{LL}$ and $\mathrm{CDH}$ conceived this study. CL provided financial and administrative support. BR and DJ performed most of the data analysis and collected the data using the CP cohort. CL provided the devices for this study. All authors discussed the results, explained them further and prepared the tables and panels for these figures. $C L, L L, C D H, B S$ and $B R$ wrote the manuscript. All authors read and approved the final manuscript.

\section{Funding}

The LFD used in the testing were provided by CL/BioSolutions services LLC.

\section{Availability of data and materials}

The datasets used and/or analysed during the current study are available from the corresponding authors on reasonable request.

\section{Ethics approval and consent to participate}

All tests were performed under a NYBC IRB approved protocol. Convalescent donor plasma was collected by the New York Blood Center (NYBC) with written consent from patients in accordance with NYBC Institutional Review Board protocols. 


\section{Consent for publication}

All authors agree to submit for consideration for publication in the journal.

\section{Competing interests}

$\mathrm{CL}$ worked with the LFD manufacturer on the Emergency Use Authorization submission to the US FDA.

\section{Author details}

${ }^{1}$ New York Blood Center Lindsley F. Kimball Research Institute, 310 E 67th Street, New York, NY 10065, USA. ${ }^{2}$ BioSolutions Services, 92 Irving Avenue, Englewood Cliffs, NJ 07632, USA. ${ }^{3}$ Department of Management and Entrepreneurship, Silberman College of Business, Fairleigh Dickinson University, Teaneck, NJ, USA. ${ }^{4}$ Weatherhead School of Management, Case Western Reserve University, Cleveland, $\mathrm{OH}, \mathrm{USA}$.

Received: 30 June 2020 Accepted: 28 July 2020

Published online: 06 August 2020

\section{References}

1. DOH N. New York State Department of Health COVID-19 Tracker. 2020

2. Chinazzi M, Davis JT, Ajelli M, Gioannini C, Litvinova M, Merler S, et al. The effect of travel restrictions on the spread of the 2019 novel coronavirus (COVID-19) outbreak. Science. 2020;368(6489):395-400.

3. Long QX, Liu BZ, Deng HJ, Wu GC, Deng K, Chen YK, et al. Antibody responses to SARS-CoV-2 in patients with COVID-19. Nat Med. 2020. https:// doi.org/10.1038/s41591-020-0897-1.

4. Wajnberg A, Mansour M, Leven E, Bouvier NM, Patel G, Firpo A, Mendu R, Jhang J, Arinsburg S, Gitman M, Houldsworth J, Baine I, Simon V, Aberg
J, Krammer F, Reich D, Cordon-Cardo C. Humoral immune response and prolonged PCR positivity in a cohort of 1343 SARS-CoV 2 patients in the New York City region. 2020. https://doi.org/10.1101/2020.04.30.20085613

5. CDC. Interim Guidelines for COVID-19 Antibody Testing: Centers for Disease Control and Prevention; 2020 https://www.cdc.gov/coronavirus/2019-ncov/ lab/resources/antibody-tests-guidelines.html.

6. Osher G, Lamb CC, Ibarra Y, Erickson-Samson D. Observational study of SARS-CoV-2 antibody immune response in a cohort of patients at a North Suburban Chicago, Illinois Physician's Practice. LymphoSign J. 2020. IPSN2020-0007.R1

7. FDA. FAQs on Testing for SARS-CoV-2: FDA; 2020 [updated 7/30/2020]. Available from: https://www.fda.gov/medical-devices/emergency-situations -medical-devices/faqs-testing-sars-cov-2.

8. Liu X, Wang J, Xu X, Liao G, Chen Y, Hu CH. Patterns of IgG and IgM antibody response in COVID-19 patients. Emerg Microbes Infect. 2020;9(1):1269-74.

9. Robbiani DF, Gaebler C, Muecksch F, Lorenzi JC, Wang Z, Cho A, Agudelo M, Barnes CO, Gazumyan A, Finkin S, Hagglof T, et al. Convergent antibody responses to SARS-CoV-2 infection in convalescent individuals. BioRxiv. 2020. https://doi.org/10.1101/2020.05.13.092619v2.

10. Ni L, Ye F, Cheng ML, Feng Y, Deng YQ, Zhao H, et al. Detection of SARSCoV-2-specific humoral and cellular immunity in COVID-19 convalescent individuals. Immunity. 2020. https://doi.org/10.1016/j.immun i.2020.04.023

\section{Publisher's Note}

Springer Nature remains neutral with regard to jurisdictional claims in published maps and institutional affiliations.
Ready to submit your research? Choose BMC and benefit from:

- fast, convenient online submission

- thorough peer review by experienced researchers in your field

- rapid publication on acceptance

- support for research data, including large and complex data types

- gold Open Access which fosters wider collaboration and increased citations

- maximum visibility for your research: over $100 \mathrm{M}$ website views per year

At BMC, research is always in progress.

Learn more biomedcentral.com/submissions 